\title{
DESAFIOS DA FORMAÇÃO DE PROFESSORES DE LÍNGUA PORTUGUESA: A RELAÇÃO ENTRE OS SABERES DISCIPLINARES E OS SABERES DA PRÁTICA
}

\author{
CHALLENGES IN THE TRAINING OF PORTUGUESE LANGUAGE TEACHERS: THE RELATION BETWEEN \\ THEORETICAL KNOWLEDGE AND PRACTICAL KNOWLEDGE
}

\author{
Nara Caetano Rodrigues* \\ Maria Izabel de Bortoli Hentz \\ Universidade Federal de Santa Catarina - UFSC
}

\begin{abstract}
RESUMO: Estudos na área da educação demonstram que a configuração dos cursos de licenciatura propiciou uma formação de professores na qual as disciplinas de conteúdos específicos não se articula(va)m com as de conteúdos pedagógicos. As resoluções 01/2002 e 02/2002, assim como o Parecer 28/2001, do Conselho Nacional de Educação (BRASIL, 2001; 2002a; 2002b), têm provocado mudanças na organização curricular dos cursos de licenciatura, particularmente quando estabelecem a carga horária para os diferentes componentes curriculares. Nesse sentido, a prática deve se constituir como componente curricular fundamental ao longo do curso, visando ao aprendizado do fazer docente. Esse aspecto das diretrizes curriculares para a formação de professores é problematizado a partir da análise da matriz curricular de três cursos de Letras de Universidades de Santa Catarina, observando algumas dimensões do Instrumento de Avaliação de Cursos CEE/SC. O que se constatou é que há diferentes formas de se implementar a carga horária de prática como componente curricular (PCC), prevista nas diretrizes: a) em diferentes disciplinas; b) de modo interdisciplinar; c) em disciplinas específicas.
\end{abstract}

PALAVRAS-CHAVE: formação de professores; saberes docentes; prática profissional; componente curricular.

ABSTRACT: Studies in Education show that the configuration of undergraduate teaching degrees have provided a kind of teacher education in which specific content subjects are not in articulation with pedagogical content subjects. Resolutions $01 / 2002$ and 02/2002, as well as Advice 28/2001 of the National Council of Education have caused significant changes in the curriculum of undergraduate courses, particularly when establishing the workload for the several curriculum subjects. In this sense, practicum should be an essential curricular component developed throughout the course, in order to enable the learning of teaching skills. This aspect of curriculum guidelines for teacher education has been challenged by means of an analysis of the curriculum of six courses of Letters of universities from Santa Catarina, in which some aspects of the Instrument of Course Evaluation CEE/SC have been examined. We could observe that there are different ways to achieve the workload of Practicum as a Curricular Component (PCC), established in the regulations: a) in different disciplines; b) in interdisciplinary mode; c) in specific disciplines. KEYWORDS: teacher education; teacher's knowledge; practicum; curriculum component.

\section{INTRODUÇÃo}

Como as discussões sobre a formação de professores começaram há mais tempo no âmbito das ciências da educação, iniciamos nossa reflexão pela formação de professores em sentido mais amplo, focalizando os saberes docentes necessários para o desenvolvimento do processo de ensino-aprendizagem e chegando à problematização da formação inicial do professor de Língua Portuguesa (LP) frente às demandas impostas pelas atuais diretrizes curriculares nacionais para os cursos de licenciatura.

Para Gauthier (1998, p. 327), a pedagogia se originou no século XVII, devido a um conjunto de fatores que desencadeou a expansão da instituição escolar. Dentre eles, o autor destaca a Reforma Protestante, a Contra-Reforma católica, o surgimento de uma nova percepção da infância e o número crescente de jovens ociosos. A pedagogia da época é descrita como

a codificação de novas maneiras de fazer dos professores experientes, maneiras de fazer formalizadas e relativas não somente ao conteúdo da matéria, mas também a todos os aspectos da sala de aula, da organização do tempo e do espaço à gestão dos comportamentos, dos micro-acontecimentos às grandes etapas que dão ritmos diversos ao desenrolar do ano letivo. Essas habilidades, conselhos práticos, atitudes e maneiras de fazer, transmitidos e legados aos professores das gerações seguintes, constituirão pouco depois um código uniforme de maneiras de fazer, uma verdadeira tradição pedagógica, uma 
espécie de dispositivo de repetição da maneira de dar aulas, tradição que será mantida, aliás, até o século XX sem modificações realmente importantes. (GAUTHIER, 1998, p. 328).

Essa tradição pedagógica, que consiste na imitação e na repetição de fórmulas ritualizadas, sem problematizá-las, será o alvo das críticas da Pedagogia Nova, surgida no início do século XX. Dessa crítica, nascem dois movimentos, denominados de "experiencial" e "experimental", sendo que este último apoiou-se na racionalidade científica e tomou como disciplina de referência a psicologia. Ao longo do século, muitas foram as disciplinas científicas que apresentaram reflexões no campo da educação, o que contribuiu para, a partir da década de 70, surgir a denominação "ciências da educação". Não obstante, muitas eram/são realizadas fora do contexto de exercício da atividade docente e seus resultados não puderam/podem ser utilizados pelos professores. Assim, tanto a tradição, duramente criticada pela Pedagogia Nova, quanto a ciência, dada a sua impossibilidade de fundamentar a ação do professor de maneira científica, não conseguem dar conta da complexidade real desse objeto que é a pedagogia. Constitui-se, dessa forma, um novo fundamento para a pedagogia, a partir da década de 80: o saber e a racionalidade do professor, que passam a ser estudados em

trabalhos que percebem o trabalho do professor como o de um profissional, ou seja, como o daquele que, munido de saberes e confrontado a uma situação complexa que resiste à simples aplicação dos saberes para resolver a situação, deve deliberar, julgar e decidir com relação à ação a ser adotada, ao gesto a ser feito ou à palavra a ser pronunciada antes, durante e após o ato pedagógico. (GAUTHIER, 1998, p. 331).

É nesse momento que começa a ser explicitada/problematizada a complexidade do saber docente, o qual está inextricavelmente ligado ao universo de trabalho do professor, pois a atividade docente consiste em fazer convergir dois grandes grupos de funções: aquelas ligadas à transmissão da matéria e aquelas ligadas à gestão das interações em sala de aula (GAUTHIER, 1998, p. 345).

Tardif (2002, p. 255, grifos do autor) define a epistemologia da prática profissional como sendo "o estudo do conjunto dos saberes utilizados realmente pelos profissionais em seu espaço de trabalho cotidiano para desempenhar todas as suas tarefas", apontando, assim, para um objeto de pesquisa que passou a merecer atenção a partir da década de 60 . O autor cita três "absurdos" presentes em boa parte dos estudos da área da educação da segunda metade do século XX:

[1] Querer estudar os saberes profissionais sem associá-los a uma situação de ensino, a práticas de ensino e a um professor [...]. É a mesma coisa que [Q] querer estudar uma situação real de trabalho, uma situação real de ensino, sem levar em consideração a atividade do professor e os saberes por ele mobilizados. Finalmente, [3] querer estudar os professores sem estudar o trabalho e os saberes deles seria um absurdo maior ainda. (TARDIF, 2002, p. 257).

Se os conhecimentos teóricos produzidos na esfera científica não consideram os saberes docentes construídos e significados nas situações de trabalho, a formação universitária acaba acentuando o distanciamento entre os saberes profissionais e os conhecimentos universitários. Para esse autor,

Essa distância pode assumir diversas formas, podendo ir da ruptura à rejeição da formação teórica pelos profissionais, ou então assumir formas mais atenuadas como adaptações, transformações, seleção de certos conhecimentos universitários a fim de incorporá-los à prática. Desse ponto de vista, a prática profissional nunca é um espaço de aplicação dos conhecimentos universitários. Ela é, na melhor das hipóteses, um processo de filtração que os dilui e os transforma em função das exigências do trabalho; ela é, na pior das hipóteses, um muro contra o qual vêm se jogar e morrer conhecimentos universitários considerados inúteis, sem relação com a realidade do trabalho docente diário nem com os contextos concretos de exercício da função docente. (TARDIF, 2002, p. 257).

Para estudar os saberes profissionais da área do ensino, é preciso que os pesquisadores façam o exercício exotópico de sair de seus postos acadêmicos, fechados em suas salas e laboratórios, e procurem "ver com os 
olhos do outro" 1 , lá no local de trabalho dos professores, como estes trabalham na sala de aula, como efetivam os programas escolares, como interagem com alunos, pais e colegas de profissão.

Tardif (2002) defende que a pesquisa universitária precisa se apoiar nos saberes dos professores para compor seu repertório de conhecimentos para a formação de professores.

Outro aspecto apontado pelo autor como problemático é o estudo do ensino desenvolvido a partir de um ponto de vista normativo, indicando o que os professores deveriam ser, saber e fazer ao invés de se interessar pelo que eles realmente são, fazem e sabem. As ciências da educação assumiram a visão sociopolítica do ensino a qual concebe os professores como um corpo da Igreja ou do Estado que, portanto, está a serviço de causas e finalidades maiores do que eles (TARDIF, 2002, p. 259).

Nessa mesma direção, fundamentada nos conceitos de professor reflexivo e de professor pesquisador (NÓVOA, 1995), Ferri defende que "as atividades de formação não podem desvalorizar o saber da experiência do professor e impor-lhe os conhecimentos ditos científicos" (FERRI, 2001, p. 3). Seguindo o raciocínio da autora, faz-se necessário que os futuros professores se apropriem dos saberes da experiência, para que, apoiados nos saberes universitários/acadêmicos/disciplinares, possam reconstruir sentidos. Na formação, segundo Nóvoa (1995), torna-se necessário investir na pessoa do professor e na valorização da experiência pedagógica com o intuito de que esses mesmos professores desenvolvam competências para contextualizar e reelaborar os conhecimentos que ensinam.

A compreensão de que os cursos de licenciatura formam os professores, mas não tornam alguém professor (GERALDI, 2010) é outro aspecto importante que se coaduna com a discussão proposta por Tardif sobre o conhecimento que deve constituir a formação de professores. Para Geraldi,

$[\ldots .$.$] nós nos formamos professores ao longo de alguns anos de estudos que adquirimos, que encorpamos,$
e que nos remodelam, nos tornam a pessoa que não éramos. Seguramente, esse tipo de formação é
consequiência de um longo processo histórico de construção da identidade profissional do professor, que
se mostra nos nossos cursos de formação. Certamente reconhecemos que desta forma nos formamos
professores. (GERALDI, 2010, p. 82).

Se, para este autor, os longos anos de estudo e preparação apenas formam o professor, cabe perguntar: o que torna alguém professor? Para Geraldi, é a relação que, como profissional, o sujeito estabelece com o conhecimento a ser ensinado e com seu outro - que é o aluno. Essa relação passa por momentos distintos, o que possibilita compreender a construção social e histórica do ser professor - esse profissional que se constitui no acontecimento da aula, na situação de interação na qual estão envolvidos professor e alunos.

Conforme constatou Rodrigues (2009), ao analisar o discurso de professores de Língua Portuguesa,

Embora o professor seja sensível aos discursos da ciência, dos pais, do autor do livro didático, da Direção da escola, do MEC, a voz que dá o horizonte do discurso do professor é a voz do aluno. Mais do que uma voz, é a voz social do grupo, é o outro que o constitui como professor, que permite ao professor se ver como tal. A voz do aluno é o excedente de visão que possibilita ao professor a sua completude - o seu ser-professor. (RODRIGUES, 2009, p. 287).

Nesse artigo, faremos algumas considerações sobre os saberes necessários para a prática da docência, a qual deve se constituir como componente curricular fundamental ao longo do curso, visando ao aprendizado do fazer docente ${ }^{2}$. Esse aspecto, também indicado nas atuais diretrizes curriculares para a formação de

\footnotetext{
${ }^{1}$ Vale ressaltar que há áreas de pesquisa, como os estudos sobre formação de professores na educação e na linguística aplicada, por exemplo, cujos pesquisadores têm se debruçado sobre as questões ligadas ao ensino e à aprendizagem de línguas na escola.

2 A motivação para refletir sobre esse tema está relacionada com a nossa atuação em instâncias diferentes e complementares da formação docente: Educação Básica e Educação Superior. De um lado, na orientação de estágio supervisionado de acadêmicos do Curso de Letras, no Departamento de Metodologia de Ensino; e, de outro, na coorientação das atividades de estágio na disciplina de Língua Portuguesa, no Colégio de Aplicação, ambos vinculados ao Centro de Educação da UFSC.
} 
professores, será problematizado a partir da análise da matriz curricular de três cursos de Letras de Universidades de Santa Catarina, observando algumas dimensões do Instrumento de Avaliação de Cursos do Conselho Estadual de Educação (CEE/SC).

\section{SABERES NECESSÁRIOS PARA A PRÁTICA DA DOCÊNCIA}

Ao longo da história de constituição da esfera escolar como espaço de ensino, o papel do mestre ou professor foi se transformando. Na Idade Média, na aprendizagem corporativa, o mestre era formado por outro mestre que determinava quando ele estava preparado para ensinar o ofício a outros aprendizes. Havia um favorecimento para que filhos de mestres também se transformassem em mestres (PETITAT, 1994).

No período compreendido entre os séculos XVI e XVIII, de acordo com Chervel (1990, p. 197), as soluções para os problemas relacionados às situações de ensino dependiam da colaboração dos mestres por meio da confrontação dos métodos, que ocorria por meio do deslocamento de regentes, da visitação de congregações e da divulgação de manuais pedagógicos. A aceleração dos processos de formação atinge um patamar mais elevado somente no século XIX, com a multiplicação dos corpos de instrutores e dos organismos de formação, a realização de conferências pedagógicas e o desenvolvimento da literatura pedagógica.

De acordo com Júlia (2001, p. 24-32), no século XVI os elementos da fé - a doutrina das verdades da salvação (ensino elementar) - eram ministrados oralmente por professores sem nenhuma formação inicial para o magistério que, devido aos baixos salários, exerciam outras atividades, como a de alfaiate. No fim do século XVII, com o objetivo de controlar os comportamentos das crianças pobres da cidade, surge a figura do irmão-professor. Mas é por influência da Reforma Luterana que começa a emergência de um perfil profissional, uma vez que os luteranos defendem uma escola laica, criada e mantida pelos Estados. Não obstante, devido à falta de uma política escolar do Estado Moderno, até fins do século XVIII as escolas continuam controladas pelas autoridades locais e pelo clero. É só com a supressão da Companhia de Jesus, quando os Estados substituem as Igrejas e as corporações municipais no controle do ensino, que a profissionalização dos professores começa a se legitimar. O professorado do ensino secundário deixa de ser escolhido pelos religiosos ${ }^{3}$ e autoridades das congregações e são introduzidos os exames ou concursos para selecionar os professores, dos quais passa a ser exigida uma base mínima de uma cultura profissional. Entretanto, "até 1880, a mesma licença permitia ensinar todas as disciplinas e mesmo a religião", pois, apesar de já haver uma diversidade de matérias de ensino escolar, a diferenciação das carreiras docentes via especialização na universidade e a definição de fronteiras entre as disciplinas só seria alcançada no começo do século XX (CHERVEL, 1990, p. 213).

O professor primário, considerado uma figura subalterna, passa a ser preparado pelas escolas normais nascidas no final do século XVIII, no domínio germânico. Essas, por sua vez, não preparam para a gestão cotidiana da sala de aula, para o corpo a corpo físico que caracteriza o trabalho nesse segmento destinado à instrução do povo. Nesse momento, acentua-se a oposição das culturas dos ensinos primário (que atendia à formação inicial obrigatória do povo) e secundário (que atendia parte das elites), configurada pela separação institucional e por finalidades completamente distintas dos dois segmentos.

No Brasil Colônia, conforme historia Romanelli (1984), a influência da Igreja sobre as instituições de ensino e a sua vinculação à educação dos filhos da elite permaneceu mesmo após a expulsão dos Jesuítas, em 1759, de Portugal e de seus domínios, com a ascensão do Marques de Pombal. No período monárquico, a

\footnotetext{
3 Os jesuítas, no âmbito da Companhia de Jesus, selecionavam os melhores alunos (inteligentes, saudáveis fisicamente e de espírito dócil) e, de modo semelhante à formação preceptoral, ensinavam o ofício de ensinar progressivamente, encarregando-os da correção de provas, elaboração de exercícios ou substituição do professor (JÚLIA, 2001, p. 27).
} 
preocupação era com a expansão do ensino superior, e assim foi reforçado o caráter propedêutico de curso preparatório do ensino secundário, ficando a educação popular abandonada.

A Constituição da República de 1891 consagrou a dualidade de sistemas configurada pela delegação à União do ensino superior e secundário e, aos Estados, do ensino primário e do ensino profissional, o qual compreendia as escolas normais de nível médio, para moças, e as escolas técnicas, para rapazes. As primeiras escolas normais foram criadas já a partir de 1930, mas só tiveram seu desenvolvimento acelerado durante o período republicano. Entretanto, como o ensino normal estava na alçada dos Estados, não havia diretrizes estabelecidas pelo Governo Federal para a formação de professores. Só em 1946 foi promulgada a Lei Orgânica do Ensino Normal (juntamente com a Lei Orgânica do Ensino Primário), oficializando as diretrizes do ensino para todo o território nacional (ROMANELLI, 1984).

Já a formação dos professores para a escola secundária, segundo Pereira (1999; 2000), passou a ser feita nas licenciaturas ${ }^{4}$, também criadas nos anos 30, nas antigas faculdades de filosofia. Os cursos eram constituídos seguindo a fórmula $3+1$, que corresponde a três anos de disciplinas de conteúdo específico, seguidos de um ano de disciplinas de natureza pedagógica. Essa forma de conceber a formação de professores é coerente com o modelo da racionalidade técnica, no qual "o professor é visto como um técnico, um especialista que aplica com rigor, na sua prática cotidiana, as regras do conhecimento científico e do conhecimento pedagógico.” (PEREIRA, 1999, p. 111-112). Tal modelo permaneceu sem alterações significativas até a década de 1990, quando a nova Lei de Diretrizes e Bases, precedida por uma onda de debates, provocou discussões de diferentes sujeitos e atores sociais sobre o novo modelo educacional e os novos parâmetros para a formação de professores, os quais serão discutidos na próxima seção.

Com relação à formação para a docência, Tardif (2002, p. 270-273) destaca alguns problemas epistemológicos do modelo universitário, que ele caracteriza como um "modelo aplicacionista de formação". Para o autor, esses cursos de formação, globalmente idealizados, seguem também um "modelo institucionalizado através de todo o sistema de práticas e de carreiras universitárias". Ele cita, como exemplo dessa institucionalização, a dissociação entre a pesquisa, a formação e a prática, as quais constituem problemáticas separadas que competem a diferentes agentes: os pesquisadores produzem os conhecimentos; os formadores transmitem esses conhecimentos e os professores aplicam-nos na prática.

Tardif (2002) aponta dois problemas fundamentais do modelo aplicacionista de formação de professores. O primeiro diz respeito ao fato de que tal modelo segue uma lógica disciplinar altamente fragmentada e especializada. As disciplinas constituem unidades autônomas fechadas em si mesmas e têm curta duração, o que não chega a gerar impacto sobre os alunos. Além disso, na lógica disciplinar, o foco é o conhecimento e não a ação: "aprender é conhecer", diferentemente da prática, na qual "aprender é fazer e conhecer fazendo". À dissociação entre o fazer e o conhecer, soma-se, ainda, a subordinação temporal e lógica do fazer ao conhecer, pois primeiro o aluno deve conhecer bem, para somente depois aplicar esse conhecimento na prática. $\mathrm{O}$ autor sintetiza esse problema dizendo que "Os conhecimentos proposicionais sobre o ensino baseados na lógica disciplinar, conhecimentos esses veiculados durante a formação, constituem, portanto, uma falsa representação dos saberes dos profissionais a respeito de sua prática." (TARDIF, 2002, p. 272).

O segundo problema apontado por Tardif é que o modelo aplicacionista de formação não considera as crenças e representações prévias que os alunos possuem a respeito do ensino e que funcionam como filtros cognitivos, sociais e afetivos por meio dos quais eles recebem e processam os conhecimentos proposicionais. Se esses filtros, que provêm da história de vida e da história escolar de cada um, não são trabalhados e ressignificados, a formação acaba tendo um impacto pequeno sobre o que pensam, creem e sentem os alunos antes do ingresso no curso universitário.

\footnotetext{
4. Vale ressaltar que, apesar de o cargo de professor de português ter sido criado, por decreto imperial, em 1871, somente nos anos 30 do século XX tem início o processo de formação do professor para tal disciplina (SOARES, 2001).
} 
A partir de algumas pesquisas sobre o ensino nos Estados Unidos, bem como das próprias pesquisas sobre o trabalho docente, Tardif (2002) apresenta algumas características dos saberes profissionais dos professores, que precisariam ser considerados na formação:

a) Os saberes profissionais dos professores são temporais - Primeiramente, porque boa parte do que os professores sabem provém de sua história de vida escolar. Eles são trabalhadores que, antes de se inserirem na profissão, já estiveram imersos em seu espaço de trabalho por aproximadamente 16 anos, o que gera uma bagagem de conhecimentos, crenças e representações sobre a prática docente, que são reativados para solucionar os problemas profissionais, quando começam a trabalhar. Por outro lado, a estruturação da prática profissional ocorre nos primeiros anos da profissão, quando o professor aprende na prática as rotinas de trabalho, desenvolvendo o saber experiencial. Os saberes profissionais são temporais, ainda, porque são utilizados e se desenvolvem no âmbito de uma carreira profissional de longa duração, que compreende dimensões identitárias e de socialização profissional.

b) Os saberes profissionais dos professores são plurais e heterogêneos - Em seu trabalho, o professor se serve de saberes provenientes de diversas fontes: de sua cultura social (história de vida e cultura escolar); de conhecimentos disciplinares adquiridos na universidade; de conhecimentos didáticos e pedagógicos de sua formação profissional; de programas, guias e manuais escolares que veiculam conhecimentos curriculares; de sua própria experiência de trabalho; da experiência de certos professores; e de tradições peculiares do ofício docente. Os saberes dos professores também são variados e heterogêneos porque formam um conjunto de conhecimentos ecléticos e sincréticos, pois, de acordo com os objetivos que procuram atingir simultaneamente, os professores utilizam os saberes de forma integrada. Finalmente, os saberes profissionais são plurais e heterogêneos em função dos diferentes tipos de objetivos que exigem diferentes tipos de conhecimento, de competência ou de aptidão. Na situação de sala de aula, os professores precisam mobilizar conhecimentos diversos a fim de atingir objetivos de natureza diversa: emocionais ligados à motivação dos alunos; sociais - ligados à disciplina e a gestão da turma; cognitivos - ligados à aprendizagem do conteúdo ensinado; e coletivos - ligados ao projeto educacional da escola.

c) Os saberes profissionais são personalizados e situados - Os professores, além de disporem, obviamente, de um "sistema cognitivo", têm uma história de vida, emoções, um corpo, poderes, uma personalidade, uma cultura ou culturas, assim, "seus pensamentos e ações carregam as marcas dos contextos nos quais se inserem". O magistério é uma das atividades e profissões que envolvem interação humana, o que implica a presença física do trabalhador no local de trabalho e sua pessoa constitui um elemento fundamental na realização do processo de trabalho na interação com os alunos. Os professores devem contar consigo mesmos, com seus recursos e suas capacidades pessoais, sua própria experiência e a de seus pares para administrar seu ambiente de trabalho. Os saberes profissionais também são situados, isto é, construídos, utilizados e significados em função de uma situação de trabalho particular, na qual os envolvidos devem negociar e compreender juntos o significado de seu trabalho coletivo, pois os significados atribuídos às situações de ensino pelos professores e alunos são elaborados e partilhados dentro dessas próprias situações.

d) O objeto do trabalho do docente são seres humanos - Por conseguinte, os saberes dos professores carregam as marcas do ser humano - mesmo que pertençam a grupos, os seres humanos existem primeiro como indivíduos. Esse fenômeno "está no cerne do trabalho dos professores, pois, embora eles trabalhem com grupos de alunos, devem atingir os indivíduos que os compõem, pois são os indivíduos que aprendem". O professor precisa ter sensibilidade e discernimento para conhecer e para compreender os alunos como indivíduos, reconhecendo suas diferenças e evitando as generalizações excessivas. O objeto humano do trabalho docente tem ainda como consequência o fato de que o saber profissional comporta sempre um componente ético e emocional. As práticas profissionais levam, muitas vezes, o indivíduo a questionar suas intenções, valores e o próprio fazer pedagógico: 
Esses questionamentos sobre a maneira de ensinar, de entrar em relação com os outros, sobre os efeitos de suas ações e sobre os valores nos quais elas se apóiam exigem do professor uma grande disponibilidade afetiva e uma capacidade de discernir suas reações interiores portadoras de certezas sobre os fundamentos de sua ação. (TARDIF, 2002, p. 268).

Dada a complexidade dos saberes mobilizados pelos professores nas situações de ensino-aprendizagem em que desenvolvem seu trabalho, no caso da formação de professores de línguas, vale refletir sobre a relação entre as ciências de referência presentes nos currículos dos cursos de Letras e o lugar destinado aos conhecimentos sobre a prática pedagógica.

Petitjean (1998), no que se refere à formação de professores para o ensino de francês - e poderíamos estender para o de LP -, defende que caberia "selecionar as teorias de referência em função de seu grau de validade explicativa em relação às competências a serem desenvolvidas e, num movimento ascensional inverso, interpelar as teorias de referência para que elas contribuam para uma melhor descrição das competências e performances dos alunos" (PETITJEAN, 1998, p. 24).

Ao comentar a distância que há entre as prescrições do currículo formal e a realidade das práticas de ensino do francês, o autor destaca que a redução dessa distância implica uma formação inicial adequada, com currículos menos carregados, para atender às diferentes e complexas demandas da escola de educação básica.

A constatação da distância entre os saberes especializados privilegiados na formação e os saberes profissionais exigidos na prática da docência provocou a necessidade de rever as diretrizes curriculares para a formação de professores nas universidades brasileiras, a partir da década de 1990.

\section{AS “NOVAS”/ATUAIS DIRETRIZES PARA A FORMAÇÃO DOCENTE}

O debate acerca da formação de professores, por muito tempo restrito ao meio acadêmico-científico, foi se ampliando e envolvendo os sistemas de ensino e os seus órgãos normativos e reguladores, de modo a possibilitar modificações significativas na legislação que regulamenta os cursos de licenciatura. O Seminário Catarinense das Licenciaturas, realizado ao longo do ano de 2007, foi ilustrativo de como os ecos desse debate propiciaram o estreitamento do diálogo entre os muitos atores do fazer pedagógico dos diferentes níveis de ensino. Esse evento foi coordenado pela Secretaria de Estado da Educação, em parceria com a Associação Catarinense das Fundações Educacionais - ACAFE, e envolveu aproximadamente 1000 participantes nas etapas regionais e estadual, representantes dos cursos de licenciatura das Instituições de Ensino Superior (gestores, professores e acadêmicos), dos diferentes sistemas e redes de ensino (professores e gestores) e dos Conselhos Municipais e Estadual de Educação.

No contexto nacional, cabe destacar o Decreto $\mathrm{N}^{\mathrm{o}}$ 6.755, de 29 de janeiro de 2009, que institui a Política Nacional de Formação de Profissionais do Magistério da Educação Básica. Esse decreto prevê a criação de fóruns estaduais permanentes de apoio à formação docente, com a finalidade de organizar os Planos Estratégicos da formação inicial e continuada dos profissionais do magistério para as redes públicas da educação básica, em regime de colaboração entre a União, o Estado e os Municípios. Em Santa Catarina, o fórum foi criado pela Portaria SED n ${ }^{\circ}$ 19, de 12 de agosto de 2009 e as Instituições que o integram são: Secretaria de Estado da Educação - SED, Conselho Estadual de Educação - CEE/SC, Ministério da Educação - MEC, Universidade Federal de Santa Catarina - UFSC, Universidade do Estado de Santa

Catarina - UDESC, Instituto Federal de Santa Catarina - IFSC, União dos Dirigentes Municipais de Educação - UNDIME, União dos Conselhos Municipais de Educação - UNCME, Associação Catarinense 
das Fundações Educacionais - ACAFE, Fundação Catarinense de Educação Especial - FCEE e Sindicato dos Trabalhadores em Educação de Santa Catarina - SINTE5.

Mas o debate acerca da formação de professores também se fez e se faz presente nos órgãos normativos e reguladores dos sistemas de ensino. As resoluções 01/2002 e 02/2002, assim como o Parecer 28/2001 do Conselho Nacional de Educação (BRASIL, 2001; 2002a; 2002b) são ilustrativos de como esses órgãos têm incorporado, em alguma medida, os resultados das pesquisas e dos debates que envolvem os cursos de licenciatura. Esses documentos vêm provocando mudanças significativas na organização curricular dos cursos de licenciatura, particularmente ao estabelecerem a carga horária para os diferentes componentes curriculares.

Não é possível, no entanto, pensar que algumas resoluções ou pareceres consigam superar in totum a tradicional dicotomia entre os conhecimentos das ciências de referência e os conhecimentos da prática pedagógica (PETITJEAN, 1998) na organização curricular dos cursos de formação de professores, até porque nesses mesmos documentos ela também se manifesta. Percebe-se, porém, a indicação de que a açãoreflexão-ação deve ser privilegiada como princípio metodológico geral no projeto pedagógico de cada curso, assim como a resolução de situações-problema deve constituir a estratégia didática para sua efetivação. Considerando-se esses princípios, as resoluções 01/2002 e 02/2002, assim como o Parecer 28/2001 estabelecem a prática pedagógica como componente curricular fundamental e, como tal, deve ser vivenciada ao longo do curso.

Das mudanças necessárias, considerando as diretrizes emanadas pelo Conselho Nacional de Educação, a que continua provocando polêmicas (tanto nas instituições formadoras como nas escolas de educação básica) é a carga horária destinada à prática como componente curricular (presente desde o início do curso) e ao estágio curricular supervisionado e a sua integralização a partir da segunda metade do curso. No contexto dessa regulamentação, o estágio é entendido como um período de aprendizado do fazer docente e, portanto, os acadêmicos devem vivenciar a Educação Básica por mais tempo, como oportunidade de se apropriarem desse saber em um contexto real6.

No Seminário Catarinense das Licenciaturas, anteriormente referido, a organização didático-pedagógica dos cursos de licenciatura e o estágio se configuraram como dimensões fundamentais em torno das quais se desenvolveu o debate. Como ponto positivo acerca da organização didático-pedagógica dos cursos, foi destacado o modelo de formação que agrega teoria, prática e reflexão com base em um conjunto de disciplinas cujo objeto de estudo e conhecimento é a construção de uma identidade profissional na docência. Como pontos que merecem atenção e investimento das instituições formadoras e dos órgãos reguladores, foram destacados: a não articulação entre teoria e prática, especialmente nos cursos noturnos; a fragmentação das disciplinas e do conhecimento, pois muitos cursos ainda mantêm a organização curricular fundamentada na perspectiva da racionalidade técnica, ou seja, no modelo $3+1$ (PEREIRA, 1999); os componentes curriculares distanciam-se do cotidiano e do contexto da educação básica; o desconhecimento da realidade da escola de educação básica, assim como da prática a ser desenvolvida em sala de aula, por parte de muitos dos professores formadores.

$\mathrm{Na}$ nossa avaliação, esses dados sugerem que a desarticulação entre os conhecimentos das ciências de referência e os conhecimentos sobre a prática pedagógica, tal como indicado em Petitjean (1998), ainda se configura como uma questão crucial na formação do profissional da educação, assim como a desarticulação da formação em nível superior com a educação básica, campo de atuação dos licenciados nas mais diferentes áreas do conhecimento, ao mesmo tempo em que corroboram a indicação da Resolução CNE/CP/2002 de

\footnotetext{
${ }^{5}$ Atualmente também integram este Fórum a Universidade Federal da Fronteira Sul - UFFS, o Instituto Federal de Educação, Ciência e Tecnologia Catarinense - IFC e a Associação Nacional pela formação dos profissionais da Educação - ANFOPE.

${ }^{6}$ Ainda que o estágio seja entendido como um período para o aprendizado do fazer docente pela configuração que assume, não será objeto de reflexão e discussão nesse texto.
} 
que a dimensão prática na formação de professores não deve ficar reduzida a um espaço isolado, desarticulado do restante do curso.

Nas palavras de Leite (2007, p. 11) "a prática deve transcender o próprio estágio, a sala de aula, e numa perspectiva interdisciplinar, deve visar ao futuro professor melhor compreensão do ambiente educacional e do contexto escolar, concorrendo para a 'formação da identidade do professor"”. Para tanto, segundo a autora, a prática como componente curricular

deve incluir diferentes atividades que propiciem ao futuro professor o conhecimento da comunidade, das famílias e dos próprios alunos. Pode ainda envolver atividades junto aos órgãos normativos e aos órgãos executivos dos sistemas estaduais e municipais de ensino, como também, junto a agências educacionais não escolares. Essas atividades que devem buscar a relação entre a teoria e a realidade exigem um movimento contínuo entre o saber e o fazer, na busca de significados na gestão, administração e resolução de situações problemas próprios do ambiente escolar. (LEITE, 2007, p. 12).

Para a autora, é preciso repensar a formação a partir do contexto de trabalho do professor, o que significa que esta não pode estar descolada ou distanciada da reflexão crítica da realidade da escola de educação básica. Nesse sentido, a prática como componente curricular, a exemplo do estágio, "deve oferecer ao aluno de licenciatura condições para que perceba que o professor é um profissional, inserido em um determinado espaço e tempo histórico, capaz de questionar e refletir sobre a sua prática, assim como sobre o contexto político e social no qual esta se desenvolve" (LEITE, 2007, p. 8).

Canário (2001) também já ressaltava que a aproximação entre a universidade e a escola de educação básica contexto real da prática do professor - precisa se fundamentar em um novo relacionamento, no qual as escolas sejam consideradas espaços fundamentais de aprendizagem profissional e não simples espaços de aplicação de teorias estudadas ao longo do curso, como foram compreendidas por muito tempo.

Formar o professor como profissional reflexivo, como propõe Nóvoa (1995), implica garantir as condições teóricas e práticas para que ele seja capaz de compreender a realidade educacional na qual está inserido e de atuar sobre esta mesma realidade, propondo alternativas pedagógicas fundamentadas em mudanças epistemológicas, resultado das reflexões da prática vivenciada no contexto de sua formação.

A seguir, passaremos à descrição e análise de algumas matrizes curriculares, objetivando a reflexão sobre a presença/indicação da prática como componente curricular nos cursos de Letras de algumas universidades situadas no estado de Santa Catarina.

\section{FOCO DE ANÁliSE: A PRÁTICA COMO COMPONENTE CURRICULAR EM CURSOS DE LETRAS}

Como já indicamos, a organização dos cursos de licenciatura com base no esquema 3 + 1 (PEREIRA, 1999), possibilitou que se desenvolvessem cursos de formação de professores nos quais as disciplinas de conteúdos específicos não se articula(va)m às de conteúdos pedagógicos.

No atual contexto, a formação de professores ainda se coloca como um desafio para as Instituições de Educação Superior (IES), que têm sob sua responsabilidade a formação inicial dos docentes; para as instâncias de regulação (como o Conselho Nacional de Educação e os Conselhos Estaduais de Educação), que estabelecem diretrizes para os cursos de formação de professores; e, para as instâncias governamentais, que têm envidado esforços em políticas de formação inicial e continuada.

As IES, de um modo geral, têm se dedicado à reelaboração de seus cursos de licenciatura. A elaboração do projeto pedagógico, assim como sua implementação, envolve a ação de muitos atores, ainda que a de alguns não se manifeste pela presença física na realização das diferentes etapas desse processo. Como exemplo, podemos destacar a ação dos autores que fundamentam teórica e metodologicamente a proposta de determinado curso e dos responsáveis pela elaboração de diretrizes legais para todas as licenciaturas no país. A produção 
do conhecimento acerca de questões relacionadas à educação e ao ensino e as necessidades de cada tempo histórico provocam mudanças nos dispositivos legais e nos projetos pedagógicos dos cursos de licenciatura. É o que vem ocorrendo desde a aprovação das resoluções 01/2002 e 02/2002, assim como do Parecer 28/2001, do Conselho Nacional de Educação.

Outro fator que pode contribuir significativamente para essas mudanças é a avaliação dos cursos de licenciatura, quer pelas comissões próprias das instituições que os ofertam, quer pelos processos externos de avaliação. Internamente, a avaliação de um curso pelos diferentes segmentos (alunos, professores, coordenação) que o constituem permite que a comissão estabeleça a relação e o contraponto de diferentes perspectivas em relação aos itens avaliados, de modo a identificar limites e possibilidades, a fim de estabelecer metas/caminhos para superação do que se apresenta como negativo e potencialização do que se apresenta como positivo. Do ponto de vista da avaliação externa, a presença de uma comissão pode constituir um significativo momento de diálogo, uma vez que tanto a instituição avaliada se beneficia das contribuições dos avaliadores - pares do fazer docente em cursos de outras instituições -, como esses conhecem outras respostas para problemáticas semelhantes.

Embora os sistemas de ensino responsáveis pela regulação da educação superior sempre tenham realizado algum tipo de avaliação dos cursos de educação superior, no contexto dos quais se situam os cursos de licenciatura, esse processo passou a ter uma maior coerência com as diretrizes nacionais estabelecidas pela Lei $n^{\circ}$ 10.861, de 14 de abril de 2004, que instituiu o Sistema Nacional de Avaliação da Educação Superior SINAES.

Como a regulação da oferta da educação superior é prerrogativa do sistema federal e dos sistemas estaduais de ensino, antes da instituição do SINAES era comum haver critérios diferentes de avaliação dos cursos superiores entre o sistema federal e os sistemas estaduais, bem como entre os diferentes sistemas estaduais de ensino. O referido sistema nacional de avaliação, decorrente da regulamentação do art. $9^{\circ}$ da LDB (Lei 9394/96), passou a atuar como um sistema nacional, de fato, na medida em que os Estados iniciaram um processo de celebração de termos de cooperação com a União para a adoção dos critérios nacionais de avaliação nos cursos sob sua jurisdição.

O processo de busca de uma coerência na avaliação dos diferentes sistemas de ensino ganhou maior eficácia com a adoção, por muitos Estados da federação, dos instrumentos avaliativos do Instituto Nacional de Pesquisa Educacional Anísio Teixeira - INEP, no contexto da consolidação do SINAES. Com isso, a observação das diretrizes nacionais para os diferentes cursos de licenciatura passou a ser mais criteriosa por parte das Instituições de Educação Superior, uma vez que passou a haver parâmetros nacionais claros de avaliação dos mesmos.

Na seção seguinte, apresentamos a análise de como vem se implementando a carga horária de prática como componente curricular em Cursos de Licenciatura em Letras de universidades públicas e comunitárias de Santa Catarina. Para essa análise, tomamos como referência o instrumento de renovação e reconhecimento de curso de graduação disponível no sítio eletrônico do $\mathrm{CEE} / \mathrm{SC}^{7}$, mais especificamente a dimensão 1 Organização didático-pedagógica: indicador 1.3 - Consistência do PPC e do currículo face às Diretrizes Curriculares Nacionais (DCN) - e a dimensão relativa aos requisitos legais: item 1 - Cumprimento das DCN.

A pesquisa é documental e, ao fazermos este estudo, pretendemos apresentar elementos que contribuam para a reflexão sobre diferentes possibilidades de implementação de currículos que visem à superação da dicotomia saberes disciplinares-saberes da prática.

${ }^{7}$ Disponível em http://www.cee.sc.gov.br/index.php?option=com_docman\&task=cat_view\&gid=34\&Itemid=55. Acesso em 11.08 .2011$. 
Os dados de análise são constituídos por projetos pedagógicos dos cursos (PPC) e por relatórios de comissões externas de avaliação, no período compreendido entre 2006 e 2010. Dos projetos pedagógicos, vamos nos ater à matriz curricular, ao ementário das disciplinas que integram a matriz curricular e às indicações e referências sobre como se efetiva, no contexto do curso, a carga horária relativa às 400 horas de prática como componente curricular. Além desses documentos, também consideramos, para fins de análise, o regulamento da organização dessa carga horária, quando de sua existência.

Ao todo foram analisados seis Projetos Pedagógicos de Cursos de Licenciatura em Letras, de universidades públicas e comunitárias de Santa Catarina. No entanto, neste texto, a caracterização e a análise da implementação da prática como componente curricular será desenvolvida com base em três ${ }^{8}$ deles, identificados como PPC1, PPC2 e PPC3, representativos das três formas distintas de organização da matriz curricular as quais chegamos a partir da análise do conjunto de PPC dos seis cursos.

Assim, o PPC1 representa os projetos dos Cursos de Letras cuja carga horária de prática como componente curricular deve ser efetivada em diferentes disciplinas; o PPC2 representa os cursos nos quais essa carga horária deve ser desenvolvida de forma interdisciplinar e articulada a uma disciplina integradora e o PPC3 refere-se ao projeto de apenas um curso em que a opção foi por criar disciplinas específicas para a implementação da carga horária de prática como componente curricular.

Na sequência, apresentamos a análise dos três projetos, considerando a forma como concebem e organizam esse aspecto da formação de professores.

\subsection{A prática como componente curricular é objeto de estudo de diferentes disciplinas da matriz curricular}

O primeiro projeto que vamos analisar é o $\mathrm{PPC}^{9}{ }^{9}$ que se refere a um Curso de Licenciatura em Letras com habilitação em Português e Inglês, ofertado em regime regular, no período noturno, ao longo de oito semestres. Na matriz curricular do projeto desse curso, as horas de prática como componente curricular estão indicadas nas disciplinas que devem designar parte da carga horária ( 1 crédito $=18$ horas/aula) para cumprir o que determinam as DCN para os cursos de licenciatura. Como não há nenhuma indicação, no item relativo à organização e desenvolvimento curricular, de como esse aspecto da formação dos futuros professores deve se efetivar ao longo do curso, buscamos outras referências no próprio projeto que possibilitassem compreender a implementação da carga horária de prática como componente curricular. Há a clara indicação do princípio da indissociabilidade do ensino, da pesquisa e extensão e da formação cidadã, como se pode ler na passagem transcrita a seguir: $O$ ensino, a pesquisa e a extensão devem ser concebidos como uma corrente na qual um componente alimenta, mas também é alimentado pelos demais. ${ }^{10}$ (PPC1, p. 18).

Conforme consta do projeto pedagógico desse curso, são diversas as ações que vinculam ensino, pesquisa e extensão e, dentre elas, destaca-se o acesso dos acadêmicos aos métodos de pesquisa na disciplina de metodologia científica no início do curso e, mais ao final, nas quatro disciplinas voltadas à elaboração do trabalho de conclusão de curso e a possibilidade de participação nos grupos de pesquisa vinculados ao curso. Nas quatro disciplinas de estágio curricular supervisionado, propõe-se a aproximação do acadêmico de Letras com a escola de educação básica, campo de atuação dos licenciandos. As oportunidades de extensão para o acadêmico de Letras são configuradas pela possibilidade de participação nos projetos de contação de

\footnotetext{
${ }^{8}$ Dos projetos que não serão aqui descritos e analisados mais detalhadamente, cabe destacar as razões da não escolha: a) dois deles estão em fase de implantação e os cursos ainda não foram avaliados por comissão externa e b) o terceiro curso já foi avaliado por comissão externa, mas tanto o PPC como o relatório da comissão não nos possibilitaram elementos suficientes para uma análise mais consistente de como a carga horária de prática como componente curricular deve ser efetivada. Cabe ressaltar, no entanto, que eles serão referidos em alguns momentos da análise a título de ilustração, complementação e até mesmo de contraposição.

${ }^{9}$ Dos seis projetos analisados, três organizam seus currículos a exemplo do PPC1.

${ }^{10}$ Optamos por indicar em itálico as citações dos projetos pedagógicos, bem como as dos relatórios das comissões de avaliação, de modo a distinguilas das citações dos textos teóricos.
} 
histórias e de incentivo à leitura do laboratório de leitura e de atuação como revisor em língua portuguesa e tradutor de inglês no laboratório de línguas.

Para verificar mais especificamente como se implementa a prática como componente curricular, analisamos as ementas das disciplinas nas quais o fazer docente deveria se constituir em objeto de estudo. Das 54 disciplinas, 25 são responsáveis por integralizar a carga horária de prática como componente curricular prevista nas resoluções, entretanto, somente em 13 delas há alguma referência explícita à prática como componente curricular, em geral o último item da ementa. A título de exemplo, podemos citar alguns desses itens: Discussão das implicações do modelo estruturalista ao ensino de línguas com base nas experiências dos alunos; Os paradigmas formal e funcional: conceitos básicos, métodos analíticos e análise das repercussões no ensino de línguas com base em memoriais descritivos; $O$ texto na sala de aula: análise de textos coletados em escolas; Fonética e fonologia aplicadas ao ensino de língua portuguesa; Análise de gramáticas utilizadas em sala de aula; Aspectos relevantes da morfologia no ensino/aprendizagem da língua; Aplicações ao ensino de língua; Articulação do conteúdo com a prática da Literatura na sala de aula do Ensino Médio; A constituição dos sujeitos e sentidos do texto: análise de discursos que circulam na escola; Aplicações no ensino de língua portuguesa: produções de atividades com enfoque semântico. Do conjunto dessas 25 disciplinas, apenas três não constituem o que se poderia considerar a base específica (Linguística e Literatura) ou, no dizer de Petitjean (1998), as disciplinas das ciências de referência, da formação do professor de Língua Portuguesa.

O tempo e o espaço para o trabalho com a dimensão prática da formação dos futuros professores estão formalizados em 25 disciplinas da matriz curricular deste curso e demarcados na ementa de 13 delas, ainda que não integralizem a carga horária total prevista no parecer CNE/CP 28/2001 e na Resolução CNE/CP 2/2002. Além disso, é possível concluir que a concretização do que está formalizado e demarcado vai depender da compreensão de cada professor acerca da importância da articulação entre os saberes disciplinares e os saberes da prática e de como viabilizá-la. Não identificamos no projeto pedagógico deste curso uma indicação clara e fundamentada que pudesse orientar de forma orgânica a ação do conjunto de professores das disciplinas responsáveis pelo estudo e análise sistemática da dimensão prática da ação docente.

Como identificamos em nossa análise do PPC1, no relatório da comissão externa de avaliação desse curso, também consta a ressalva de que o total da carga horária de PCC, bem como a sua operacionalização não estão explicitadas no projeto pedagógico. Nesse mesmo relatório, a análise indica que não há clareza de como efetivamente a prática como componente curricular se concretiza no desenvolvimento das diferentes disciplinas. Por outro lado, ainda segundo o relatório, há atividades que consideram a dimensão prática da formação, mas estas se restringem à análise de Livros Didáticos (LD).

Na nossa compreensão, se considerarmos que o material a ser utilizado como recurso didático (e aqui se inclui o livro texto) faz parte da esfera escolar e está intrinsecamente ligado ao fazer do professor no cotidiano das aulas de Língua Portuguesa (e há estudos na LA nessa direção ${ }^{11}$ ), entendemos que, em alguma medida, a prática vem se constituindo como objeto de estudo no contexto desse curso de formação. Saber analisar um livro didático, identificar concepções que o fundamentam são saberes importantes a um professor, mas há de se destacar que há outras facetas do fazer docente na educação básica, espaço de atuação dos futuros professores, que precisam se constituir em objeto de estudo.

Como indicado por Canário (2001), as escolas precisam ser percebidas como espaços nos quais também se aprende sobre o fazer docente e não apenas como lócus de aplicação de teorias estudadas ao longo do curso. Nesse sentido, a carga horária de prática como componente curricular precisa ser melhor compreendida,

\footnotetext{
${ }^{11}$ Alguns exemplos de estudos realizados por pesquisadores da área da LA sobre o LD encontram-se em: Rojo e Batista (2003) e Dionisio e Bezerra (2005).
} 
planejada e organizada para que os saberes profissionais exigidos na prática da docência se constituam efetivamente como conhecimentos a serem apreendidos na formação inicial dos futuros professores.

Uma possibilidade para essa efetivação seria a participação dos alunos nas atividades de extensão e de pesquisa que se desenvolvem nos laboratórios do curso, mas tanto o que consta do projeto pedagógico do curso como do relatório da comissão de avaliação sugere que apenas os alunos bolsistas participam mais ativamente dessas atividades e alguns poucos alunos voluntários. A maioria dos alunos participa de atividades decorrentes desses projetos, tais como seminários, palestras, feiras, eventos culturais. Parece-nos importante ressaltar, no entanto, que a participação nessas atividades também constitui parte da carga horária do curso e, em nosso entender, é um importante aspecto da formação dos futuros professores previsto na Resolução $\mathrm{CNE} / \mathrm{CP}$ 2, como atividades acadêmico-científico-culturais.

Por fim, na análise do projeto pedagógico deste curso, em relação aos projetos de outros dois cursos (do conjunto dos seis analisados) que propõem esta mesma organização para a efetivação das 400 horas de PCC, identificamos alguns aspectos que os distinguem. Dentre eles, destacam-se dois: o primeiro diz respeito à padronização de 1 crédito $(18 \mathrm{~h} / \mathrm{a})$ para cada uma das disciplinas responsáveis por tomar a prática docente como componente curricular, independentemente do número de créditos da disciplina, assumida no PPC1, enquanto que nos projetos dos outros dois cursos não se observa este tipo de padronização. A segunda diferença refere-se à concepção de prática como componente curricular indicada em itens específicos nos projetos dos dois cursos que não foram aqui detalhados, conforme indicado anteriormente, e não explicitada no PPC1.

\subsection{A prática como componente curricular é objeto de estudo interdisciplinar}

O segundo projeto a ser descrito e analisado é o do Curso de Letras, habilitação em Língua Portuguesa, Inglesa e Espanhola (PPC2), ofertado na modalidade presencial, em regime regular (com aulas de segunda a sexta-feira, no período noturno) e em regime especial (com aulas às sextas- feiras à noite e sábados, no período matutino e vespertino, em oito semestres). O PPC2 é representativo de cursos que prevêem a integralização da carga horária de prática como componente curricular, prevista na Resolução 02/ $\mathrm{CNE} / \mathrm{CP} / 2002$, em disciplinas específicas que constam da matriz curricular e pela atribuição de parte da carga horária de disciplinas que se articulam às específicas, constando como um tópico da ementa.

A matriz curricular deste curso é constituída de 47 disciplinas, sendo que, em 15 delas, há a indicação de parte da carga horária para a prática como componente curricular e, em cinco disciplinas do total, a prática educativa vivenciada na realidade escolar se constitui em objeto de estudo. Ressaltamos, no entanto, que a indicação de como são integralizadas as 400 horas de prática como componente curricular, prevista na legislação que regulamenta os cursos de licenciatura, não consta do projeto pedagógico do curso, mas do regulamento das atividades práticas educativas a ser referido mais detalhadamente na sequência.

No regulamento ${ }^{12}$, a prática como componente curricular é entendida como aquelas atividades que ocorrerem no interior das áreas ou das disciplinas que constituírem os componentes curriculares de formação cuja dimensão prática visem a enriquecer o processo formativo do professor e devem ocorrer ao longo de todo o processo formativo. Nesse curso de Letras, delimita-se o total de 27 créditos, o que corresponde a 405 horas a serem efetivadas como parte da carga horária em disciplinas que compõem o currículo do curso, constando como um item da ementa - Pesquisa e Prática Educativa - e no componente curricular denominado Seminários de Práticas em Letras.

A disciplina Seminários de Práticas em Letras é articuladora das disciplinas da fase cuja prática se constitui como componente curricular. $\mathrm{Na}$ análise da ementa dessa disciplina, nos cinco semestres em que se desenvolve, observamos que o foco é a aproximação com a realidade escolar, tendo como referência

${ }^{12}$ Como o regulamento também se constitui em dado de análise, as citações desse documento serão indicadas em itálico. 
diferentes disciplinas, ou seja, em cada uma das fases a ênfase é para uma das áreas implicadas na formação de um professor de LP (a literatura infantil; as contribuições da linguística e da teoria da literatura para o ensino-aprendizagem de línguas e de literatura; a literatura brasileira; o ensino-aprendizagem de línguas estrangeiras; os processos de ensino-aprendizagem de línguas). Na análise das ementas das disciplinas de cada fase que devem se ocupar da dimensão prática da formação dos licenciandos em Letras e que constituem, na nossa avaliação, um eixo interdisciplinar, o que verificamos, no entanto, é que em apenas uma de todo o conjunto consta, como último item, a indicação "Pesquisa e prática educativa", tal como definido no regulamento.

Além de indicar as disciplinas e a carga horária de cada uma delas, o regulamento também prevê a socialização dos resultados dos projetos de atividades práticas vivenciadas ao longo do curso, a ser efetivada em seminários e também pela publicação de artigos ou de monografias, a critério do colegiado de cada campus em que o curso é ofertado. A organização dos seminários de socialização será de responsabilidade apenas dos professores da disciplina Seminários de Práticas em Letras, enquanto a orientação para elaboração dos projetos e dos artigos ou das monografias será de responsabilidade desses professores em articulação com os professores das disciplinas que desenvolvem as atividades de pesquisa e prática educativa, em cada fase, no Curso de Letras.

Conforme consta do relatório da comissão externa de avaliação, os planos de ensino e os diários de classe dos professores não possibilitam a compreensão de como, no contexto do curso, se integralizam as 400 horas de prática como componente curricular, ainda que os professores tenham apresentado exemplares de projetos e de relatórios de atividades práticas vivenciadas ao longo do curso, elaborados pelos próprios alunos. No entanto, com base neste mesmo relatório, é possível compreender que a prática como componente curricular está sendo implementada no contexto da disciplina Seminários de Práticas em Letras, mas não em outras que, com esta, deveriam compor uma proposta de trabalho articulado e interdisciplinar.

Do ponto de vista do regulamento das atividades práticas educativas, constatamos que tanto a concepção assumida para a PCC, como a organização curricular proposta, remetem ao que os autores com os quais dialogamos neste texto indicam para a formação de professores: a interação entre os saberes profissionais e os saberes especializados, tendo em vista a compreensão do ambiente educacional e do contexto escolar, de um modo geral, e da complexidade dos saberes mobilizados pelos professores nas situações de ensinoaprendizagem, de modo particular.

Aqui, novamente podemos recorrer às características dos saberes profissionais dos professores que, segundo Tardif (2002), devem ser considerados na formação. Para este autor, os saberes profissionais dos professores caracterizam-se, dentre outros aspectos, pela pluralidade e pela heterogeneidade, na medida em que em uma determinada situação de sala de aula mobilizam diversos conhecimentos, considerando que os objetivos a serem alcançados envolvem o projeto pedagógico da escola, a motivação dos alunos, a disciplina e a gestão da turma e a aprendizagem do conteúdo a ser ensinado.

As informações constantes no projeto pedagógico do curso e no relatório da comissão de avaliação são insuficientes para demonstrar a concretização da carga horária de prática como componente curricular do modo como está prevista no regulamento do curso.

$\mathrm{O}$ que constatamos na análise do $\mathrm{PPC} 2$, na tentativa de implementar a carga horária de prática como componente curricular, é ilustrativo da dificuldade de efetivamente se articular uma proposta teoricamente bem fundamentada com a sua viabilização em ações concretas. Como bem destaca Furlanetto (2007), a passagem da teoria à prática não pode ser idealizada e nem imposta aos professores (e aqui se incluem também os de nível superior); precisa ser resultado de um processo que produz aprendizado. 
Na nossa avaliação, a formação para a dimensão prática da docência em uma perspectiva interdisciplinar e ao longo do curso é a mais condizente com o referencial teórico por nós assumido e com as indicações oficiais, entretanto ainda há um caminho a ser percorrido para que de fato de efetive.

\subsection{A prática como componente curricular é objeto de estudo de disciplinas específicas}

$\mathrm{O}$ PPC3 é o projeto Pedagógico do Curso de Letras Habilitação em Língua Portuguesa e Respectivas Literaturas e representa o terceiro modelo de organização curricular no que se refere à integralização da prática como componente curricular. No projeto deste curso, a opção foi pela criação de disciplinas específicas para cumprir o que determinam as diretrizes para os cursos de licenciatura no que se refere à dimensão prática da formação, conforme explicitaremos a seguir.

A matriz curricular do curso em questão é constituída de 40 disciplinas ministradas ao longo de sete semestres letivos. Desse total, uma disciplina que se desenvolve num continuum ao longo dos cinco primeiros semestres do curso de Letras, bem como dos demais cursos de licenciatura da instituição, é responsável pela integralização das 405 horas de prática como componente curricular ${ }^{13}$.

No projeto pedagógico do curso, a disciplina que integraliza a carga horária de prática como componente curricular está assim especificada no ementário: a) no primeiro período: Compreensão da identidade e profissionalidade docente. Contextualização de ambientes escolares e não escolares. Procedimentos e processos de investigação da prática docente em ambientes escolares e não escolares; b) no segundo período: Compreensão da identidade e profissionalidade docente em ambientes de aprendizagem. Procedimentos e processos de investigação da prática docente em ambientes de aprendizagem; c) no terceiro período: Elementos e processos da docência na organização e desenvolvimento curricular. Planejamento; procedimentos e processos da prática docente na organização e desenvolvimento curricular. Prática da docência; d) no quarto período: Compreensão da identidade e profissionalidade docente nos aspectos legais, carreira, desafios e perspectivas. Plano de ação: da problematização à execução. Documentação e registro da pesquisa em educação; e e) Prática pedagógica: conceito, características e elementos. Materiais didáticos: análise e produção. Documentação e registro da prática pedagógica.

$\mathrm{Na}$ análise da ementa da disciplina nas diferentes fases, constatamos que o foco do primeiro período é o estudo do ambiente educacional; do segundo período, é o estudo do ambiente de aprendizagem; no terceiro período, o foco é o estudo da organização curricular das escolas de ensino fundamental e médio; no quarto período, são os aspectos legais da carreira docente e o desenvolvimento profissional do professor e o foco do quinto período são os aspectos implicados na prática pedagógica.

Em um primeiro momento, podemos entender que essa organização curricular se fundamenta em uma compreensão de formação de professor que prepara o licenciando para chegar à sala de aula, com base em uma visão de todos os processos que envolvem a escola, ou seja, contemplando, de certa forma, os diferentes saberes exigidos do professor nas situações de ensino-aprendizagem (TARDIF, 2002) com as quais vai se deparar na sua prática docente.

No projeto desse curso, a prática como componente curricular se organiza em torno dos conceitos de identidade e profissionalidade docente, de modo a transcender o fazer do professor no espaço da sala de aula, conforme indicado no Parecer CNE/CP 28/2001 - o que também é ressaltado por Leite (2007). Apesar da importância da ênfase em tais aspectos da formação docente, percebemos que aspectos relacionados à prática específica do professor de Língua Portuguesa não são contemplados na ementa da disciplina responsável pela integralização da carga horária da PCC ao longo das cinco fases em que é ministrada.

\footnotetext{
${ }^{13}$ Essa a disciplina é ofertada de forma diferenciada em relação às demais: possui parte da sua carga horária em campo (instituições formais e não formais de ensino), uma vez por semana, no matutino, vespertino ou noturno, de acordo com a escolha do acadêmico, e a outra parte aos sábados, quinzenalmente, intercalando encontros presenciais e virtuais.
} 
Isso também foi ressaltado no relatório da comissão de avaliação deste curso na indicação de que a proposta não contempla as especificidades da área da linguagem, podendo enquadrar-se em quaisquer cursos de licenciatura. Visando à articulação entre as disciplinas das ciências de referência do curso de Letras e a disciplina responsável pela dimensão prática da formação docente, constam do referido relatório as seguintes sugestões de aprimoramento do projeto pedagógico desse curso: a) inserção de discussões acerca da linguagem (língua, discurso, fala, gênero, elaboração didática da língua e literatura, texto etc), sobretudo nas disciplinas que se propõem a ser constitutivas da área de práticas como componente curricular [...] para não incorrer em perda de identidade do graduando de Letras e b) a reavaliação do papel dessas disciplinas na formação do professor de Letras, inclusive, quem sabe, dando a elas um caráter de especificidade.

Os aspectos relativos ao PPC3 aqui analisados possibilitam entender que no projeto desse curso se assume, de um lado, o fazer docente como um dos princípios formativos, tal como indicado nas diretrizes para a formação de professores e em autores como Petitjean (1998), Tardif (2002) e Leite (2007), entre outros. De outro lado, no entanto, aspectos da especificidade do fazer docente do professor de Língua Portuguesa podem estar ficando à margem do processo de formação. Não obstante, não aprofundamos essa discussão, tendo em vista que nosso foco de análise recaiu sobre o modo como a prática como componente curricular está sendo implementada nos cursos, por meio da análise de alguns documentos institucionais (PPC e pareceres das comissões de avaliação).

Dessa forma, a análise do PPC3 foi relevante para nosso estudo, considerando que apresenta uma organização curricular que difere dos demais projetos de curso no que diz respeito à implementação da prática como componente curricular, pois é o que mais evidencia a preocupação com a formação da identidade e profissionalidade docente - aspectos essenciais na distinção de um curso de licenciatura de um curso de bacharelado.

\section{CONSIDERAÇÕES FINAIS}

Nos seis projetos analisados e, mais especificamente, nos três aqui referidos, constatamos o movimento no sentido do cumprimento da determinação legal relativa às 400 horas de prática como componente curricular. No primeiro projeto (PPC1), a organização da matriz curricular sugere o que prevê a resolução que regulamenta a carga horária dos cursos de licenciatura, ou seja, que a prática não se constitua como um espaço isolado, desarticulado do restante do curso. Entretanto, constatamos que essa organização pode não se viabilizar no contexto das ações que se desenvolvem na implementação do projeto pedagógico do curso.

No segundo projeto (PPC2), observamos a proposição de que os conhecimentos sobre os saberes profissionais sejam objeto de estudo interdisciplinar pelo diálogo entre disciplinas de prática e disciplinas das ciências de referência em cada uma das fases do curso, mas, pelos dados analisados, ainda não é possível visualizar como essa proposta se concretiza nas ações de professores e alunos desse curso.

No terceiro projeto (PPC3), constatamos que identidade e profissionalidade docente se configuram como conceitos fundamentais do projeto do curso de licenciatura, o que contempla o princípio da prática como componente curricular, previsto nas diretrizes curriculares para a formação de professores. No entanto, a opção por criar disciplinas específicas, cujos saberes profissionais exigidos na prática da docência se constituem em objeto de estudo, pode configurar a criação de um espaço isolado, desarticulado do restante do curso, uma vez que as especificidades da dimensão prática na área da linguagem podem não estar sendo suficientemente contempladas nessa proposição de organização curricular.

Pela análise dos dados, não constatamos de modo explícito a "articulação intrínseca com o estágio supervisionado", em nenhum dos projetos, conforme recomendado pelo Parecer CNE/CP 28/2001. Entretanto, o PPC1 e o PPC3 preveem na matriz curricular parte da carga horária de estágio concomitante às atividades de PCC, o que pode viabilizar essa articulação. 
Verificamos, assim, que as alterações procedidas nos cursos de licenciatura a partir do movimento desencadeado pelas mudanças normativas desde a década de 1990, embora tenham provocado significativas alterações formais nos referidos cursos, não significaram, de fato, um funcionamento de todo articulado entre os saberes das ciências de referência ou saberes disciplinares e os saberes da prática. Assim, em matrizes curriculares que contemplam as disposições normativas que superam o modelo 3+1 (PEREIRA, 1999), não é raro observar práticas que conservam, se não de todo, mas em parte significativa, o funcionamento alinhado com este modelo, o que pode ocorrer em cursos cuja matriz curricular se organize de modo semelhante à do PPC1.

Olhando a questão por um outro ângulo, se considerarmos que, no modelo $3+1$, a formação docente era caracterizada pela apropriação do conhecimento de um bacharel somado aos saberes metodológicos para o ensino de Língua Portuguesa na escola de educação básica, é preciso pensar sobre uma questão suscitada a partir de tal mudança: o que significa a formação docente considerando o que preveem as atuais diretrizes para os cursos de licenciatura e os estudos da área? Um desdobramento possível seria a formação de um especialista em transmissão de determinados conhecimentos que são transformados em conteúdos de ensino, mas ele mesmo (o futuro professor) com conhecimentos menores das ciências de referência na área específica de sua formação. Isso pode acontecer em cursos cuja organização da matriz curricular se assemelhe à do PPC3.

Considerando esse questionamento, cabe às agências formadoras tratar a questão com muito equilíbrio e com foco no perfil do profissional docente que a sociedade necessita em nosso tempo. Se, por um lado, a formação docente deve caminhar na direção da criação de uma identidade profissional, superando a condição de complementação do bacharelado, é não menos importante que esse profissional docente não tenha os conhecimentos das ciências de referência de sua área específica de formação diminuídos. Estabelecendo uma relação dessa problemática com a área da Língua Portuguesa: se o professor dessa disciplina não precisa ser, forçosamente, um linguista, também não pode ser um especialista em ensino de algo que não conheça suficientemente e de que não tenha se apropriado para tomá-lo como objeto de ensino.

Esse aspecto não pôde ser aprofundado nesse artigo, tendo em vista que nosso foco recaiu sobre as formas de implementação da carga horária de prática como componente curricular em cursos de Letras de Universidades de Santa Catarina, ou seja, sobre as possibilidades de formação do graduando no que se refere à organização da dimensão da prática pedagógica como objeto de estudo no decorrer do curso.

A investigação do currículo dos cursos no que diz respeito às especificidades da área da linguagem certamente constitui objeto de estudo de extrema relevância - o que demandaria uma nova análise dos projetos pedagógicos, investigando toda a matriz curricular dos cursos, a exemplo do que fizeram Silva, Assis e Matêncio (2001), ao analisarem o curso de Letras em implantação na PUC-Minas, focalizando os seguintes aspectos: $1^{\circ}$ ) Formação do Usuário; $2^{\circ}$ ) Formação do Usuário/Especialista; $3^{\circ}$ ) Formação do Professor Usuário e Especialista.

Pela análise dos projetos pedagógicos dos cursos, foi possível percebermos algumas possibilidades de implementação da carga horária de prática como componente curricular nas matrizes curriculares, quais sejam: a) a carga horária de PCC está distribuída em diferentes disciplinas; b) as $400 \mathrm{~h}$ de PCC foram organizadas de modo interdisciplinar, ou seja, parte dessa carga horária fica sob a responsabilidade de uma disciplina específica (que se desenvolve nas cinco primeiras fases do curso) articulada a disciplinas específicas de cada uma das áreas implicadas na formação de professor de LP; e c) a criação de disciplinas específicas para dar conta da carga horária de PCC. Ainda, pelos pareceres da comissão de avaliação, tivemos acesso ao modo como os cursos são avaliados no que diz respeito à Organização didáticopedagógica, no que tange à consistência do PPC e do currículo face às Diretrizes Curriculares Nacionais, bem como no que se refere à dimensão relativa a um dos requisitos legais: item 1 - Cumprimento das DCN. 
Entretanto, constatamos que o corpus analisado possui como limitação o fato de que não nos permitiu saber como cada instituição está efetivando as atividades relativas a essa dimensão da formação dos futuros professores no decorrer dos cursos, pois não tivemos acesso às práticas propriamente ditas. Dessa forma, sinalizamos a relevância de estudos que investiguem, por um período de tempo mais longo - numa abordagem etnográfica, talvez -, a realização dessas práticas e a sua validade na formação dos profissionais que se formarem nos cursos analisados.

\section{REFERÊNCIAS}

BRASIL. Conselho Nacional de Educação. Parecer CNE/CP 28/2001. Brasília, 2001.

, Conselho Nacional de Educação. Resolução CNE/CP 1. Brasília, 2002.

, Conselho Nacional de Educação. Resolução CNE/CP 2. Brasília, 2002.

CANÁRIO, R. O papel da prática profissional na formação inicial e contínua de professores. In:

CONGRESSO BRASILEIRO DE QUALIDADE NA EDUCAÇÃO, 2001, Brasília. Anais...

CHERVEL, A. História das disciplinas escolares: reflexões sobre um campo de pesquisa. Teoria \&̊ educação, n. 2, p. 177-229, 1990.

DIONISIO, A. P.; BEZERRA, M. A. (Orgs.). O livro didático de português: múltiplos olhares. 3. ed. Rio de Janeiro: Lucerna, 2005.

FERRI, C. Currículo multicultural e a formação do professor: a busca por um profissional culturalmente comprometido. In: REUNIÃO ANUAL DA ANPED, 24., 2001, Caxambu. Anais...

FURLANetTo, M. M. Práticas discursivas: desafio no ensino de Língua Portuguesa. In: CORREA, D. A.; SALEH, P. B. de O. (Orgs.). Práticas de letramento no ensino: leitura, escrita e discurso. São Paulo: Parábola Editorial; Ponta Grossa: UEPG, 2007.

GAUTHIER, C. [et al.]. Por uma teoria da pedagogia: pesquisas contemporâneas sobre o saber docente. Ijui: Ed. UNIJJUI, 1998.

GERALDI, J. W. A aula como acontecimento. São Carlos: Pedro \& João Editores, 2010.

JÚLIA, D. A cultura escolar como objeto histórico. Revista brasileira de história da educação, n. 1, p. 9-43, jan./jun. 2001.

LEITE, Y. U. F. A formação de professores nos cursos de licenciatura: algumas diretrizes e práticas, 2007.

NÓVOA, A. Diz-me como ensinas, dir-te-ei quem és e vice-versa. In: FAZENDA, I. (Org.). A pesquisa em educação e as transformações do conhecimento. Campinas: Papirus, 1995.

PEREIRA, J. E. D. As licenciaturas e as novas políticas educacionais para a formação docente. Educação छ sociedade, ano $\mathrm{xx}$, n. 68, p. 109-125, dez. 99.

Formação de professores - pesquisa, representações e poder. Belo horizonte: Autêntica, 2000.

PETITAT, A. Produção da escola/produção da sociedade: análise sócio-histórica de alguns momentos decisivos da evolução escolar no ocidente. Tradução de Eunice Gruman. Porto Alegre: Artes médicas, 1994.

PETITJEAN, A. La transposition didactique en français. Pratiques, Metz: Siège Social, n. 97-98, juin p. 734, 1998.

RODRIGUES, N. C. O discurso do professor de língua portuguesa no processo de reestruturação curricular: uma construção dialógica. Tese (Doutorado em Lingüística) - Programa de Pós-Graduação em Lingüística, Universidade Federal de Santa Catarina, Florianópolis, 2009.

ROJO, R.; BATISTA, A. A. G. (Orgs.). Livro didático de língua portuguesa, letramento e cultura da escrita. Campinas, SP: Mercado de Letras, 2003.

ROMANELLI, O. História da educação no Brasil (1930/1973). Petrópolis: Vozes, 1984. 
SILVA, J. Q. G.; ASSIS, J. A.; MATÊNCIO, M. L. M. Formação inicial e letramento do professor de português: uma proposta em implantação. In: KLEIMAN, A. B. (Org.). A formação do professor: perspectivas da lingüística aplicada. Campinas, SP: Mercado de Letras, 2001.

SOARES, M. Que professor de português queremos formar? Boletim da Associação Brasileira de Lingüística, Fortaleza: Imprensa Universitária/UFC, v.[?], p. $211-218,2001$.

TARDIF, M. Saberes docentes e formação profissional. Petrópolis: Vozes, 2002.

Recebido em 18/og/11. Aprovado em 07/12/11. 